\title{
Antifibrotic effects of tocotrienols on human Tenon's fibroblasts
}

\author{
Christoph Tappeiner • Alexander Meyenberg • David Goldblum • Daniel Mojon • \\ Jean-Marc Zingg • Kalanithi Nesaretnam • Monika Kilchenmann • Beatrice E. Frueh
}

Received: 27 December 2008 /Revised: 27 May 2009 / Accepted: 27 July 2009 /Published online: 14 August 2009

(C) Springer-Verlag 2009

\begin{abstract}
Purpose To compare the antifibrotic effect of vitamin E isoforms $\alpha-, \gamma-$, and $\delta$-tocotrienol on human Tenon's fibroblasts (hTf) to the antimetabolite mitomycin C.

Methods Antifibrotic effects of $\alpha-(40,60,80,100$, and $120 \mu \mathrm{M}), \gamma-(10,20,30$, and $40 \mu \mathrm{M})$ and $\delta$-tocotrienol $(10$, $20,30$, and $40 \mu \mathrm{M})$ on hTf cultures were evaluated by performing proliferation, migration and collagen synthesis assays. Whereas for vitamin $\mathrm{E}$ the exposure time was set to 7 days to mimic subconjunctival application, cultures were exposed only $5 \mathrm{~min}$ to mitomycin C $100 \mu \mathrm{g} / \mathrm{ml}$ to mimic intraoperative administration. Cell morphology (phase contrast microscopy) as an assessment for cytotoxicity and cell density by measuring DNA content in a fluorometric
\end{abstract}

The authors have full control of all primary data and agree to allow the journal to review their data if requested.

C. Tappeiner $(\bowtie) \cdot$ A. Meyenberg $\cdot$ M. Kilchenmann $\cdot$ B. E. Frueh Department of Ophthalmology, Inselspital, University of Bern, 3010 Bern, Switzerland

e-mail: christoph.tappeiner@insel.ch

D. Goldblum

Department of Ophthalmology,

University Hospital Basel, University Basel,

Basel, Switzerland

D. Mojon

Department of Ophthalmology, Kantonsspital,

St. Gallen, Switzerland

J.-M. Zingg

Institute of Biochemistry and Molecular Medicine,

University of Bern,

Bern, Switzerland

K. Nesaretnam

Malaysian Palm Oil Board,

Kuala Lumpur, Malaysia assay to determine proliferation inhibition was performed on day 0,4 , and 7 . Migration ability and collagen synthesis of fibroblasts were measured.

Results All tested tocotrienol isoforms were able to significantly inhibit hTf proliferation in a dose-dependent manner (maximal inhibitory effect without relevant morphological changes at day 4 for $\alpha$-tocotrienol $80 \mu \mathrm{M}$ with $36.7 \%$ and at day 7 for $\alpha$-tocotrienol $80 \mu \mathrm{M}$ with $42.6 \%$ compared to control). Degenerative cell changes were observed in cultures with concentrations above $80 \mu \mathrm{M}$ for $\alpha$ - and above $30 \mu \mathrm{M}$ for $\gamma$ - and $\delta$-tocotrienol. The highest collagen synthesis inhibition has been found with $80 \mu \mathrm{M} \alpha$-tocotrienol (62.4\%) and no significant inhibition for mitomycin $\mathrm{C}$ (2.5\%). Migration ability was significantly reduced in cultures exposed to $80 \mu \mathrm{M}$ $\alpha$ - and $30 \mu \mathrm{M} \gamma$-tocotrienol (inhibition of $82.2 \%$ and $79.5 \%$, respectively, compared to control) and also after mitomycin C treatment $(60.0 \%)$. Complete growth inhibition without significant degenerative cell changes could only be achieved with mitomycin $\mathrm{C}$.

Conclusion In vitro, all tested tocotrienol isoforms were able to inhibit proliferation, migration and collagen synthesis of human Tenon's fibroblasts and therefore may have the potential as an anti-scarring agent in filtrating glaucoma surgery.

Keywords Vitamin E - Tocotrienol - Antifibrotic effect . Tenon's fibroblast $\cdot$ Filtrating glaucoma surgery . Mitomycin C

\section{Introduction}

Postoperative fibrosis of the filtering bleb or of the surgical fistula is a known cause of failure in glaucoma surgery $[1,2]$. Tenon's fibroblasts are assumed to be the 
main component of scar tissue in glaucoma surgery [2]. Antimetabolites as mitomycin $\mathrm{C}$ and 5-fluorouracil are currently used as anti-scarring drugs in glaucoma surgery, especially in eyes with an elevated risk of bleb scarring, but may hold the risk of postoperative complications, e.g., ocular hypotonia (bleb leakage), conjunctival necrosis of the filtering bleb, or endophthalmitis because of cytotoxic side effects [3-10]. Although recent studies have shown encouraging results for mitomycin $\mathrm{C}$ with a relatively low complication rate [11], alternative agents may still be useful. In cancer research, the antiproliferative and apoptotic effects of different vitamin $\mathrm{E}$ forms have been shown. Vitamin E acts as an antioxidant with neuroprotective, antithrombotic, anti-inflammatory and antineoplastic effects through its involvement in the intracellular signaling pathway [12-16]. Vitamin $\mathrm{E}$ is the generic name for two subclasses (tocopherols and tocotrienols), which itself consist of different isoforms. Vitamin $\mathrm{E}$ inhibits the proliferation of human Tenon's capsule fibroblasts in vitro [17]. In a previous in vitro study of our group, only $\alpha$ tocotrienol showed antiproliferative effects without significant toxicity on human Tenon's fibroblasts compared to $\alpha$-tocopherol, $\alpha$-tocopheryl-acetate, and $\alpha$-tocopherylsuccinate. A $50 \%$ growth inhibition could be achieved using $50 \mu \mathrm{M}$ of $\alpha$-tocotrienol [18]. Higher (and therefore eventually more effective) concentrations have not been tested. Based on prior studies [19-21] $\gamma$ - und $\delta$-isoforms of tocotrienol may even have a better antiproliferative effect than $\alpha$-tocotrienol. Therefore, the aim of this study was to evaluate the tocotrienol isoform with the highest antifibrotic effect compared to mitomycin $\mathrm{C}$ in vitro. For this purpose, we performed a proliferation, cell migration, and collagen deposition assay. Degenerative cell changes produced by vitamin $\mathrm{E}$ isoforms and mitomycin $\mathrm{C}$ were assessed by phase contrast microscopy.

\section{Materials and methods}

\section{Reagents}

RRR- $\alpha-$, RRR- $\gamma-$, and RRR- $\delta$-tocotrienol $(\alpha-\mathrm{T} 3, \gamma-\mathrm{T} 3, \delta-\mathrm{T} 3)$ were a kind gift from the Malaysian Palm Oil Board (Kuala Lumpur, Malaysia). Vitamin E forms were dissolved in ethanol absolute and then stored light-protected at $4^{\circ} \mathrm{C}$. Mitomycin $\mathrm{C}$ was purchased from Kyowa (distributed by Roche Pharma, Reinach, Switzerland) and dissolved freshly in phosphate-buffered saline (PBS) before use.

\section{Cell cultures}

Explants of human Tenon's capsule were obtained from seven patients at the time of cataract surgery. All patients gave their informed consent before inclusion in the study, which was approved by the local ethics committee and conformed to the provisions of the Declaration of Helsinki. The seven different human Tenon fibroblast cultures were thawed and placed in $25-\mathrm{cm}^{2}$ tissue culture flasks containing Dulbecco`s minimal essential medium (DMEM) supplemented with L-glutamine $(584 \mathrm{mg} / \mathrm{l})$, sodium pyruvate $(100 \mathrm{mg} / \mathrm{l})$, glucose $(1,000 \mathrm{mg} / \mathrm{l})$, penicillin $(60 \mathrm{U} / \mathrm{ml})$, streptomycin $(60 \mu \mathrm{g} / \mathrm{ml})$ and $10 \%$ fetal calf serum (FCS). None of the seven donors, aged 68-93 years, had antiglaucomatous, antimetabolite, or any other ocular treatment, or ocular surgery before the corneo-scleral cataract surgery, when Tenon specimens were taken. Cultures were maintained in a humidified $5 \%$ $\mathrm{CO}_{2}$ incubator at $37^{\circ} \mathrm{C}$. Confluent cultures were trypsinized, centrifuged, and repassaged. The above medium was changed twice per week. As quantified by trypan blue dye exclusion method, viability was always more than $95 \%$. For the assays, third- to fifth-passage cells were used. All assays were performed on all cell lines in triplicate.

\section{Cell proliferation assay}

Fibroblasts were seeded at a density of 1,500 cells/well in 96-well tissue culture plates (black/clear-bottom, Corning Life Sciences), with each well containing $200 \mu \mathrm{l}$ of culture medium. Fibroblasts were washed with PBS $24 \mathrm{~h}$ after plating and incubated for another $48 \mathrm{~h}$ with DMEM containing $0.2 \%$ FCS to induce growth arrest [2]. At day 0 , cells were rinsed with PBS and cell growth was restimulated with adding fresh DMEM/10\% FCS. Tocotrienols were immediately diluted to the indicated concentrations $(40,60,80,100$, and $120 \mu \mathrm{M} \alpha$-tocotrienol, $10,20,30$, and $40 \mu \mathrm{M} \gamma$-tocotrienol and 10, 20,30, and 40 $\mu \mathrm{M} \delta$-tocotrienol) in above media. Cells treated with an equivalent amount of ethanol absolute $(0.8 \mu \mathrm{l} / \mathrm{well})$ were included as control.

Mitomycin C was dissolved in PBS to concentrations of 10,100 , and $400 \mu \mathrm{g} / \mathrm{ml}$. Growth-arrested cells were exposed for exactly $5 \mathrm{~min}$ to $100 \mu \mathrm{l} /$ well mitomycin C solution. Fibroblasts were then gently washed with PBS alone and fed with $200 \mu \mathrm{l} /$ well DMEM/10\% FCS again. Multiple rinsing with PBS was not performed since a decrease in cell density was observed in preliminary studies. PBS-treated cultures served as control. The plates were then incubated for 7 days at $37^{\circ} \mathrm{C}$ in $5 \% \mathrm{CO}_{2}$ in a humidified air atmosphere. No media was changed during this time.

Cell morphology was studied at day $0,1,4$, and 7 using phase contrast light microscopy (Leica DMIRB research microscope, Leica Microsystems, Wetzlar, Germany). Photomicrographs were obtained with a color camera (Kappa 
CF15 MC, Kappa Messtechnik, Gleichen, Germany) connected to a video printer (Sony UP-5200MDP, Sony, Schlieren, Switzerland). Images were evaluated by a masked investigator.

As recently described in detail [18], cell density was finally determined with a fluorometric assay (CyQUANT Cell Proliferation Assay Kit, Molecular Probes, distributed by JURO Supply, Lucerne, Switzerland) measuring DNA content of each well at days 0,4 , and 7 .

\section{Collagen synthesis assay}

Collagen content was analyzed with a Sircol Soluble Collagen Assay (Biodye Science, Cologne, Germany) for cell cultures 4 days after exposure to $\alpha$-tocotrienol, $\delta$ tocotrienol, $\gamma$-tocotrienol (control: exposure to ethanol abs. $0.8 \mu \mathrm{l})$ and mitomycin $\mathrm{C}(100 \mu \mathrm{g} / \mathrm{ml}$, exposure time $5 \mathrm{~min}$;
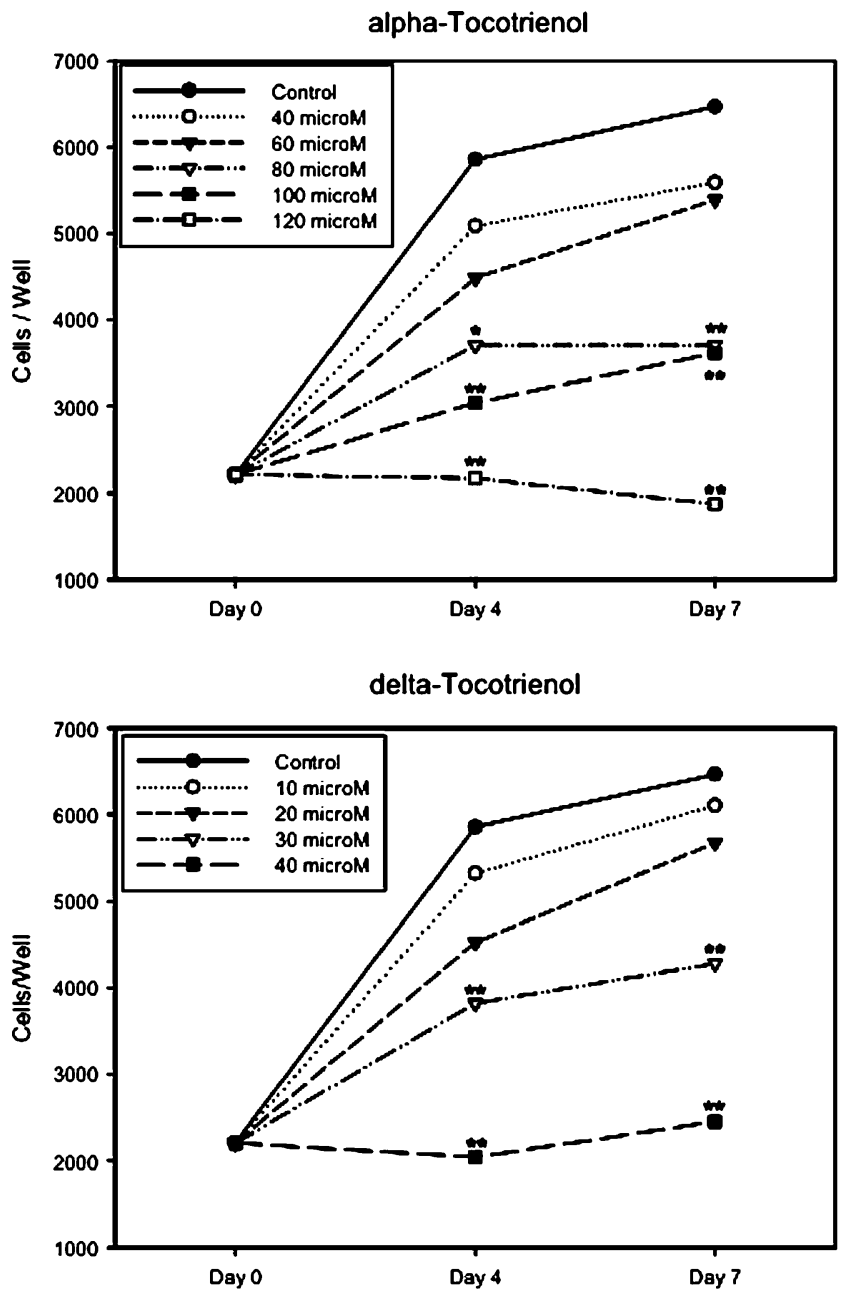

Fig. 1 Effects of incubation with different tocotrienols in variable concentrations for 7 days or exposure to mitomycin $\mathrm{C}$ for $5 \mathrm{~min}$ on human Tenon's fibroblast proliferation. A fluorometric assay determined proliferation by DNA content quantification at days 0,4 , and 7 . control: exposure to PBS). Sirius red binds specifically to soluble collagen and can be quantified with a colorimeter.

\section{Cell migration assay}

Effect of tocotrienol and mitomycin $\mathrm{C}$ on migration ability of Tenon's fibroblasts was tested with a CytoSelect 96-well Cell Migration and Invasion Assay (Cell Biolabs, Inc., distributed by JuroScience $\mathrm{GmbH}$, Lucerne, Switzerland) 2 days after exposure to tocotrienols or mitomycin $\mathrm{C}$. The migration assay kit contains polycarbonate membrane inserts $(8-\mu \mathrm{m}$ pore size $)$ in a 96-well plate. The membrane is a barrier discriminating cells with migration towards chemoattractants in the medium above the membrane. These cells were then dissociated from the membrane, and then a lysis and DNA-extraction is performed and cell count determined with a cytofluorometer as described above.
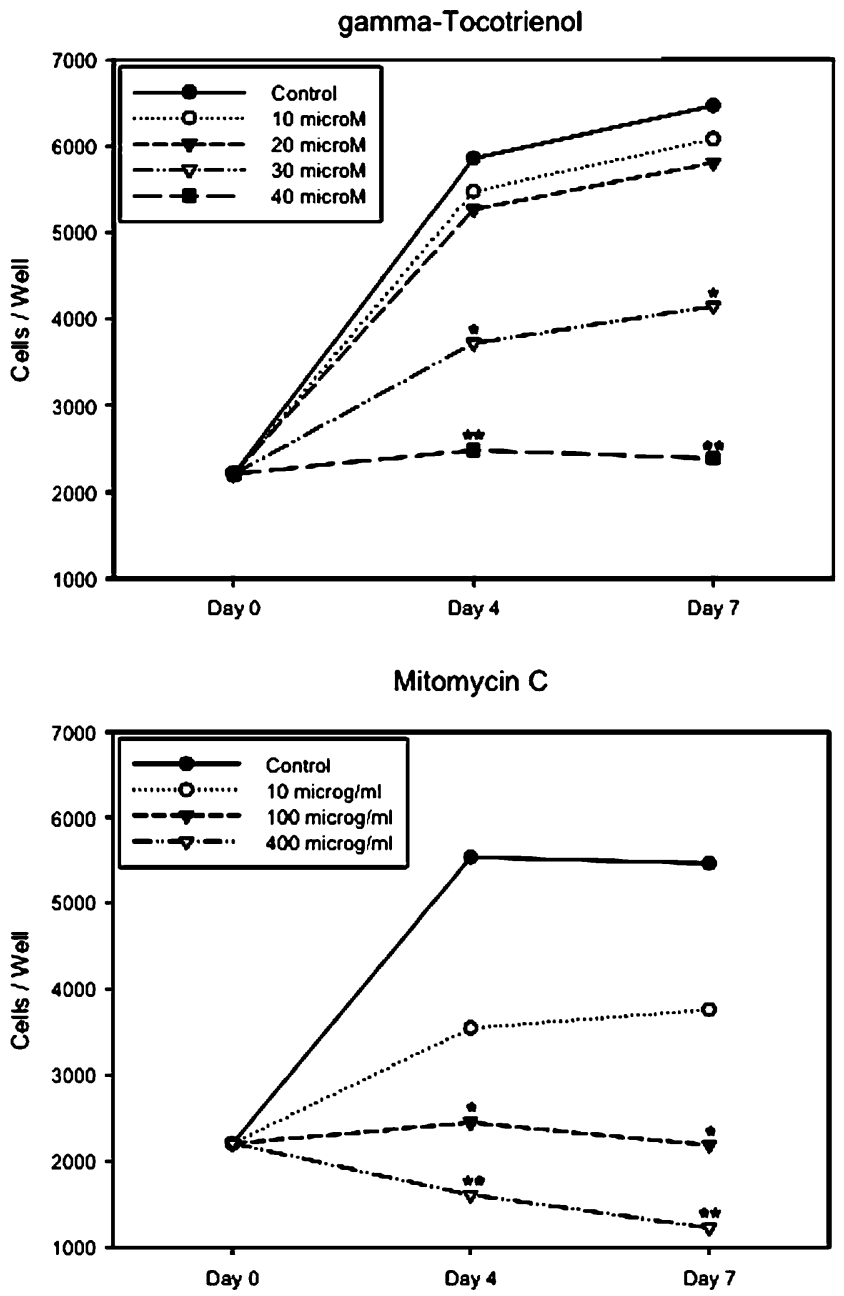

Means of cell numbers/well of seven different cell cultures in triplicate are presented. Significantly reduced values, compared to control, are marked with one $(p<0.05)$ or two $(p<0.01)$ stars 
Statistical analysis

The relationship between the fluorescence signal and the number of cells/well was very strongly linear (Pearson correlation coefficient $r=0.99$ ). Results of the proliferation assay are therefore presented as the mean number of cells/well. Inhibition of proliferation, migration, and collagen synthesis were also expressed as percentages of inhibition compared to control. Differences between control and compound values were analyzed by Friedman's test followed by the nonparametric Dunnett's test based on rank sum as post-hoc analysis. Wilcoxon rank-sum test was used when appropriate. The criterion for statistical significance was $p<0.05$.

\section{Results}

Cell proliferation and morphology

Figure 1 and Table 1 summarize the results of the proliferation assay. All tested tocotrienol forms were able to significantly inhibit fibroblast proliferation at days 4 and 7 ,

Table 1 Effects of incubation with different tocotrienols in variable concentrations for 7 days or exposure to mitomycin $\mathrm{C}$ for $5 \mathrm{~min}$ on human Tenon's fibroblast migration $(\mathrm{M})$, proliferation $(\mathrm{P})$, and collagen synthesis $(\mathrm{C})$ expressed in percentages of inhibition compared to control group at specific time points (days 2, 4, and 7)

\begin{tabular}{|c|c|c|c|c|}
\hline & \multirow{2}{*}{$\begin{array}{l}\text { Day } 2 \\
\% \mathrm{M}\end{array}$} & \multicolumn{2}{|c|}{ Day 4} & \multirow{2}{*}{$\begin{array}{l}\text { Day } \\
\% \mathrm{P}\end{array}$} \\
\hline & & $\% \mathrm{P}$ & $\% \mathrm{C}$ & \\
\hline \multicolumn{5}{|l|}{$\alpha$-tocotrienol } \\
\hline $40 \mu \mathrm{g} / \mathrm{ml}$ & 20.7 & 13.2 & -0.7 & 13.6 \\
\hline $60 \mu \mathrm{g} / \mathrm{ml}$ & 57.7 & 23.5 & 33.0 & 16.7 \\
\hline $80 \mu \mathrm{g} / \mathrm{ml}$ & 82.2 & 36.7 & 62.4 & 42.6 \\
\hline $100 \mu \mathrm{g} / \mathrm{ml}$ & n.a. & 48.1 & n.a. & 44.1 \\
\hline $120 \mu \mathrm{g} / \mathrm{ml}$ & n.a & 63.0 & n.a. & 71.0 \\
\hline \multicolumn{5}{|l|}{$\gamma$-tocotrienol } \\
\hline $10 \mu \mathrm{g} / \mathrm{ml}$ & n.a. & 6.5 & n.a. & 6.0 \\
\hline $20 \mu \mathrm{g} / \mathrm{ml}$ & n.a. & 10.1 & n.a. & 10.3 \\
\hline $30 \mu \mathrm{g} / \mathrm{ml}$ & 79.5 & 36.5 & 56.5 & 35.9 \\
\hline $40 \mu \mathrm{g} / \mathrm{ml}$ & n.a. & 33.3 & n.a. & 42.5 \\
\hline \multicolumn{5}{|l|}{$\delta$-tocotrienol } \\
\hline $10 \mu \mathrm{g} / \mathrm{ml}$ & n.a. & 9.2 & n.a. & 5.6 \\
\hline $20 \mu \mathrm{g} / \mathrm{ml}$ & n.a. & 22.8 & n.a. & 12.3 \\
\hline $30 \mu \mathrm{g} / \mathrm{ml}$ & 57.1 & 34.8 & 60.4 & 33.8 \\
\hline $40 \mu \mathrm{g} / \mathrm{ml}$ & n.a. & 65.1 & n.a. & 62.0 \\
\hline \multicolumn{5}{|l|}{ mitomycin $\mathrm{C}$} \\
\hline $10 \mu \mathrm{g} / \mathrm{ml}$ & n.a. & 35.8 & n.a. & 31.2 \\
\hline $100 \mu \mathrm{g} / \mathrm{ml}$ & 25.7 & 55.8 & 2.5 & 60.0 \\
\hline $400 \mu \mathrm{g} / \mathrm{ml}$ & n.a. & 71.0 & n.a. & 77.6 \\
\hline
\end{tabular}

Significant results $(p<0.05)$ are marked in bold and effects occurred in a dose-dependent manner. Strong antiproliferative effects but no relevant degenerative cell changes were observed in cultures treated with $80 \mu \mathrm{M} \alpha-\mathrm{T} 3$, $30 \mu \mathrm{M} \gamma-\mathrm{T} 3$, and $30 \mu \mathrm{M} \delta$-T3. At these concentrations, cell densities were statistically comparable at day $4(\alpha-\mathrm{T} 33,709 \pm$ 1,394 (mean \pm SD) cells/well, $\gamma$-T3 3,723 $\pm 2,160$ cells/well, $\delta$-T3 $3,820 \pm 2,063$ cells/well; $p=0.87)$ and day $7(\alpha-\mathrm{T} 3$ $3,714 \pm 1,524$ cells/well, $\gamma$-T3 $4,147 \pm 1,781$ cells/well, $\delta$-T3 $4,281 \pm 2,186$ cells/well; $p=0.57$ ) between all three tocotrienol forms. There was, however, considerable variation of the antiproliferative effect of all three tocotrienol forms between the seven different cell lines.

At higher concentrations, all tocotrienol forms led to nuclear and cytoplasmic condensation (Fig. 2).

Five-minute exposure to $100 \mu \mathrm{g} / \mathrm{ml}$ mitomycin C resulted in complete growth inhibition without affecting cell morphology (day 0 , control 2,208 \pm 720 cells/well; day 7, $100 \mu \mathrm{g} / \mathrm{ml}$ mitomycin C 2,187 \pm 647 cells/well; Wilcoxon test: $p=0.81$ ). Viability of cultures treated with $400 \mu \mathrm{g} / \mathrm{ml}$ mitomycin C was severely compromised (Fig. 2). Since $\alpha$-tocotrienol 80 $\mu \mathrm{M}, \delta$-tocotrienol $30 \mu \mathrm{M}$ and $\gamma$-tocotrienol $30 \mu \mathrm{M}$ were the tocotrienol concentrations with the best antiproliferative effect without relevant degenerative cell changes, only these concentrations were used in the further assays.

\section{Collagen production}

Comparing collagen content of different cell cultures (Fig. 3, Table 1) after exposure to tocotrienol and mitomycin $\mathrm{C}$ revealed significant inhibition of collagen synthesis for $\alpha$-tocotrienol $80 \mu \mathrm{M}, \gamma$-tocotrienol $30 \mu \mathrm{M}$ and $\delta$-tocotrienol $30 \mu \mathrm{M}$ (Friedman ANOVA, $p=0.0002$; Dunnmatt post-hoc test $p<0.05$, each) with the highest inhibition for $80 \mu \mathrm{M} \alpha$-tocotrienol, whereas mitomycin $\mathrm{C}$ did not inhibit collagen synthesis (Wilcoxon one-tailed test; $p=0.23$ ). Collagen content in the mitomycin $\mathrm{C}$ control (PBS) did not differ from that of the tocotrienol control (ethanol) (Wilcoxon two-tailed test; $p=0.47$ ).

\section{Cell migration ability}

Migration ability (Fig. 4, Table 1) was significantly reduced in the proliferation assay exposed to $\alpha$ tocotrienol $80 \mu \mathrm{M}$ and $\gamma$-tocotrienol $30 \mu \mathrm{M}$ compared to the ethanol control (Dunnett post-hoc test, $p<0.01$, each; Friedman ANOVA, $p<0.0001)$ and also for the mitomycin $\mathrm{C}$ assay compared to the PBS control (Wilcoxon onetailed test; $p=0.02$ ). No significant inhibition of cell migration could be shown for $\alpha$-tocotrienol 40 and 60 $\mu \mathrm{M}$ and $\delta$-tocotrienol $30 \mu \mathrm{M}(p>0.05$, each). There was no significant difference between the tocotrienol (ethanol) and the mitomycin $\mathrm{C}$ control group (PBS) (Wilcoxon twotailed test; $p=0.58$ ). 
Fig. 2 Phase contrast photomicrographs of human Tenon's fibroblasts on day 7 of the proliferation assay. a control; b $400 \mu \mathrm{g} / \mathrm{ml}$ mitomycin C; c $80 \mu \mathrm{M} \alpha$-tocotrienol; d $120 \mu \mathrm{M} \alpha$-tocotrienol; e $30 \mu \mathrm{M}$ $\gamma$-tocotrienol; f $40 \mu \mathrm{M} \gamma$ tocotrienol; g $30 \mu \mathrm{M}$ $\delta$-tocotrienol; h $40 \mu \mathrm{M} \delta$ tocotrienol. (representative photographs were obtained from fibroblasts in the center of the well. Magnification: all x 50)
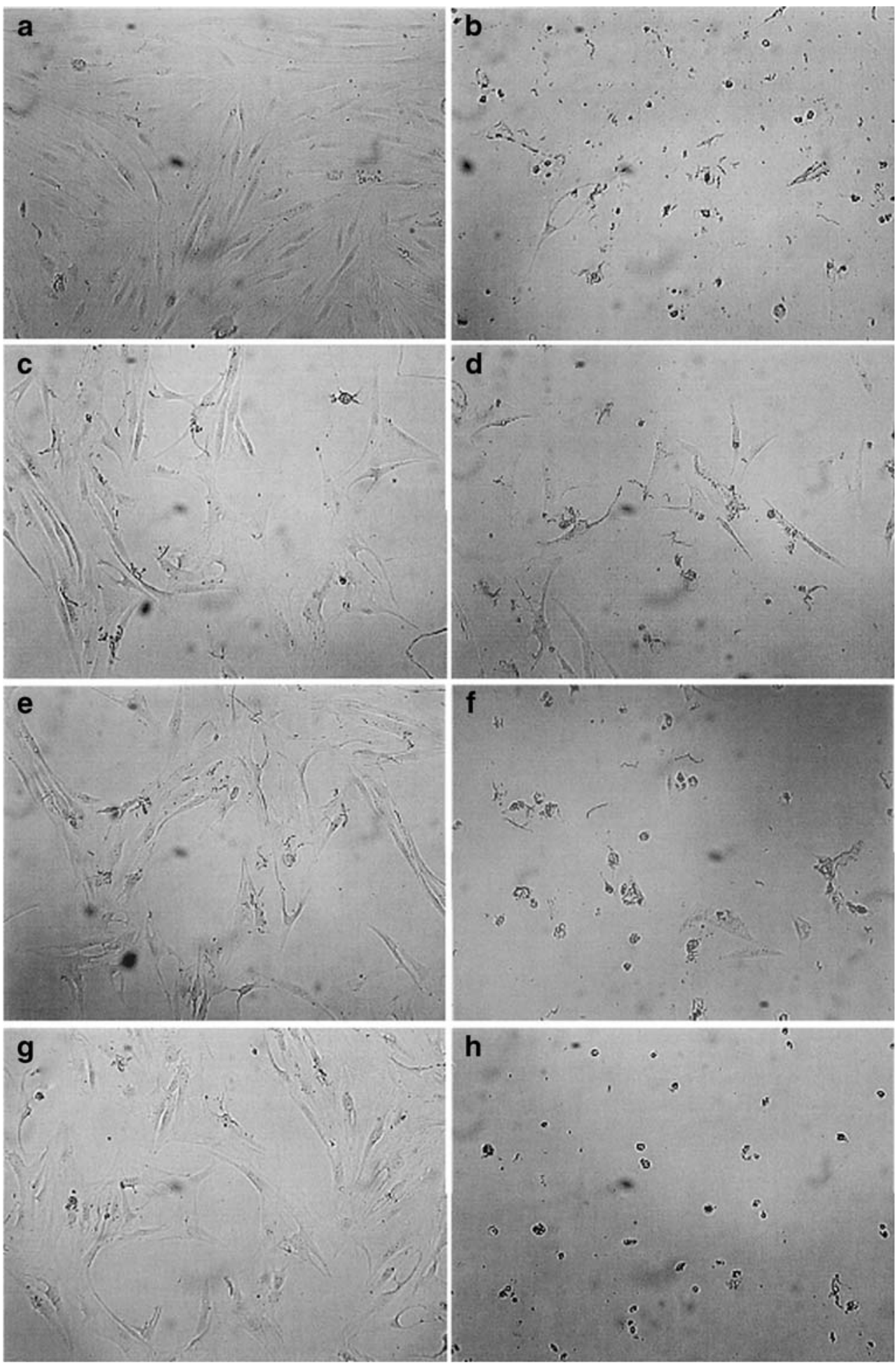

\section{Discussion}

The outcome of filtrating glaucoma surgery depends on the amount of wound healing and scarring. In a review of Lama et al., pathways involved in wound healing after glaucoma surgery are described, including vascular leakage, coagulation, cellular migration, granulation tissue, and scar formation [22].
Antimetabolites such as mitomycin $\mathrm{C}$ and 5-fluorouracil are used in filtrating glaucoma surgery to reduce bleb scarring in patients at risk for postoperative bleb failure [3-5]. Due to their cytotoxic effectiveness, hypotony and endophthalmitis may occur $[10,23]$. The dose-dependent effect of mitomycin $\mathrm{C}$ on apoptosis was shown by Crowton et al. [24]. Although experience with mitomycin $\mathrm{C}$ revealed an 


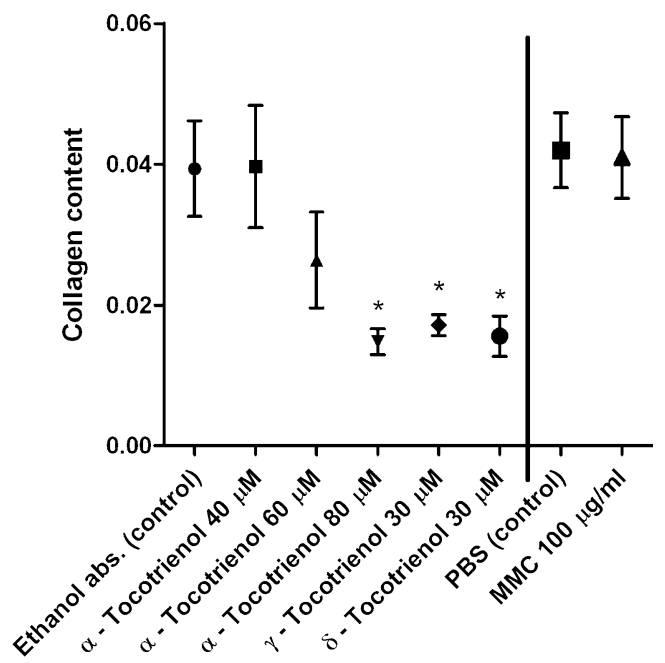

Fig. 3 Collagen content in cell cultures 4 days after exposure to tocotrienol and mitomycin $\mathrm{C}$ showing significant collagen synthesis inhibition with $\alpha$-totoctrienol $80 \mu \mathrm{M}, \gamma$-tocotrienol $30 \mu \mathrm{M}$, and $\delta$-tocotrienol $30 \mu \mathrm{M}(* p<0.05$, each) and no significant inhibition for mitomycin $\mathrm{C} 100 \mu \mathrm{M}$

acceptable safety profile $[25,26]$, alternative antiproliferative agents with less cytotoxic and cell degenerative effects compared to mitomycin C would still be needed.

In prior studies, vitamin $\mathrm{E}$ isoforms have revealed an antifibrotic potential $[17-19,21]$. Based on these findings, we evaluated the effects of different tocotrienol isoforms and concentrations on human Tenon's fibroblasts regarding inhibition of proliferation, migration, and collagen synthesis, revealing a significant antifibrotic effect for all tested isoforms.

This study focused on inhibition of proliferation, migration, and collagen synthesis, whereas other possible factors involved in wound-healing are not fully covered. Prior studies have also evaluated the effects of vitamin E isoforms on angiogenesis, apoptosis, and cytotoxic effects

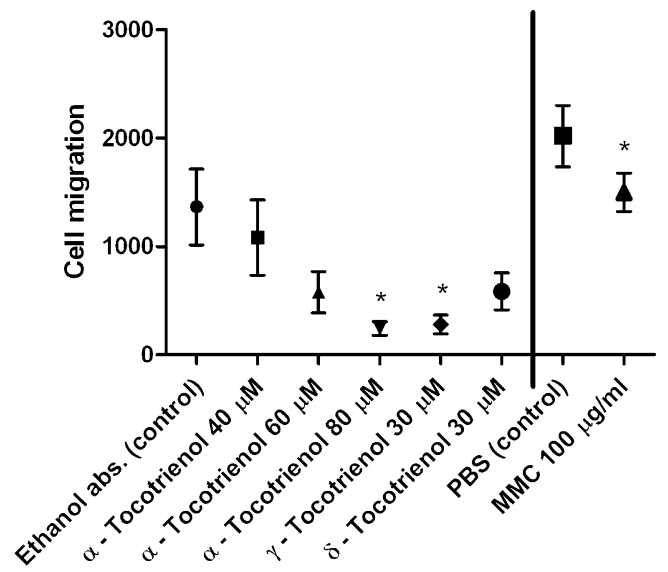

Fig. 4 Cell migration assay ( $8 \mu \mathrm{m}$ pore size; migration time $48 \mathrm{~h}$ ) for different tocotrienol isoforms/concentrations and mitomycin $\mathrm{C}$. (* $p<0.05)$
[27-30]. In a previous study of our group, the application of tocotrienol at a concentration of $100 \mu \mathrm{M}$ did not lead to an increase of glucose 6-phosphate dehydrogenase release as a measure for dying cells [18]. However, synthetic forms of vitamin $\mathrm{E}$ such as $\alpha$-tocopheryl-succinate led to significant increased G6PD levels. Considering $\alpha$ tocotrienol, degenerative cell changes were only observed after repeated application of $50 \mu \mathrm{M}$. In the present study, 80 $\mu \mathrm{M} \alpha$-tocotrienol showed a significant anti-proliferative effect without relevant morphologic changes as well.

Exposure times of hTf to tocotrienols (7 days) and mitomycin $\mathrm{C}(5 \mathrm{~min})$ have been chosen on purpose to be different in our study. During glaucoma filtration surgery, the application time of mitomycin $\mathrm{C}$ is commonly limited to a few minutes. Such a short-time application is unlikely to be suitable for tocotrienols. To the best of our knowledge, it is difficult to formulate a type of tocotrienol capable of realizing a sufficiently high and stable concentration such as needed in an intraoperative application of a few minutes as cellular uptake of tocotrienols is rather a matter of hours than minutes [31]. We therefore used a long-term application approach, which clinically could be obtained for example with a subconjunctival injection of the compound. Our results should encourage for further dose-finding and toxicity studies, as in-vitro concentrations are not directly portable to in-vivo use. As mitomycin $\mathrm{C}$ at a concentration of $100 \mu \mathrm{g} / \mathrm{ml}$ revealed the best effect without significantly toxicity, we decided to chose only this concentration for migration and collagen synthesis assays.

Whereas in our study mitomycin $\mathrm{C}$ as well as $\alpha$-tocotrienol $80 \mu \mathrm{M}$ and $\gamma$-tocotrienol $30 \mu \mathrm{M}$ significantly reduced cell migration of hTf, the antiproliferative effect of mitomycin C was higher compared to tocotrienol. On the other hand, mitomycin C (100 $\mu \mathrm{g} / \mathrm{ml}, 5 \mathrm{~min}$ exposure time) did not reveal significant inhibition of collagen production in contrast to tocotrienol ( $\alpha$-tocotrienol $80 \mu \mathrm{M}, \gamma$-tocotrienol $30 \mu \mathrm{M}$ and $\delta$-tocotrienol $30 \mu \mathrm{M})$. Because of this advantage, tocotrienol may have a certain potential as an agent for filtrating glaucoma surgery as collagen synthesis is an important factor for bleb and surgical fistula scarring in glaucoma filtrating surgery $[32,33]$. The results of our study are encouraging for further research as tocotrienols may offer the potential as an alternative agent to currently used anti-scarring drugs as mitomycin $\mathrm{C}$ or 5-fluorouracil. As tocotrienol isoforms are lipid-soluble agents, subconjunctival drug application could be difficult and an appropriate carrier substance may have to be used.

In vitro, all tested tocotrienol isoforms have revealed good antiproliferative effectiveness on human Tenon's fibroblasts. Further in vitro and in vivo studies will be necessary to evaluate the safety and the potential role of tocotrienol as a mean to prevent bleb failure in filtrating glaucoma surgery. 
Acknowledgements The authors thank A. Azzi, Vascular Biology Laboratory at Tufts University, Washington, for his critical review of the manuscript.

Conflicts of interest Tappeiner C: none; Meyenberg A: none, Goldblum D: none; Mojon D: none; Zingg JM: none; Nesaretnam $\mathrm{K}$ : employee of the Malaysian Palm Oil Board, no proprietary interests; Kilchenmann M: none; Frueh BE: none

\section{References}

1. Addicks EM et al (1983) Histologic characteristics of filtering blebs in glaucomatous eyes. Arch Ophthalmol 101(5):795-798

2. Jampel HD et al (1988) Cellular proliferation after experimental glaucoma filtration surgery. Arch Ophthalmol 106(1):89-94

3. Kitazawa $Y$ et al (1991) Trabeculectomy with mitomycin. A comparative study with fluorouracil. Arch Ophthalmol 109 (12):1693-1698

4. Palmer SS (1991) Mitomycin as adjunct chemotherapy with trabeculectomy. Ophthalmology 98(3):317-321

5. Scott IU et al (1998) Outcomes of primary trabeculectomy with the use of adjunctive mitomycin. Arch Ophthalmol 116(3):286291

6. Jampel HD, Pasquale LR, Dibernardo C (1992) Hypotony maculopathy following trabeculectomy with mitomycin C. Arch Ophthalmol 110(8):1049-1050

7. Lehmann OJ et al (2000) Risk factors for development of posttrabeculectomy endophthalmitis. Br J Ophthalmol 84(12):1349-1353

8. Membrey WL et al (2000) Glaucoma surgery with or without adjunctive antiproliferatives in normal tension glaucoma: 1 intraocular pressure control and complications. Br J Ophthalmol 84(6):586-590

9. Mietz H et al (1994) Extraocular application of mitomycin C in a rabbit model: cytotoxic effects on the ciliary body and epithelium. Ophthalmic Surg 25(4):240-244

10. Smith S, D'Amore PA, Dreyer EB (1994) Comparative toxicity of mitomycin $\mathrm{C}$ and 5-fluorouracil in vitro. Am J Ophthalmol 118 (3):332-337

11. Wilkins M, Indar A, Wormald R (2005) Intra-operative mitomycin C for glaucoma surgery. Cochrane Database Syst Rev, 2005(4): p. CD002897

12. Jiang Q, Ames BN (2003) Gamma-tocopherol, but not alphatocopherol, decreases proinflammatory eicosanoids and inflammation damage in rats. Faseb J 17(8):816-822

13. Mishima K et al (2003) Vitamin E isoforms alpha-tocotrienol and gamma-tocopherol prevent cerebral infarction in mice. Neurosci Lett 337(1):56-60

14. Tasinato A et al (1995) d-alpha-tocopherol inhibition of vascular smooth muscle cell proliferation occurs at physiological concentrations, correlates with protein kinase $\mathrm{C}$ inhibition, and is independent of its antioxidant properties. Proc Natl Acad Sci USA 92(26):12190-12194

15. Unchern $S$ et al (2003) The effects of vitamin $E$ on platelet activity in beta-thalassaemia patients. Br J Haematol 123(4):738-744
16. Wu K et al (2001) Inhibitory effects of RRR-alpha-tocopheryl succinate on benzo(a)pyrene (B(a)P)-induced forestomach carcinogenesis in female mice. World $\mathrm{J}$ Gastroenterol 7 (1):60-65

17. Haas AL et al (1996) Vitamin E inhibits proliferation of human Tenon's capsule fibroblasts in vitro. Ophthalmic Res 28(3):171175

18. Meyenberg A et al (2005) Tocotrienol inhibits proliferation of human Tenon's fibroblasts in vitro: a comparative study with vitamin E forms and mitomycin C. Graefes Arch Clin Exp Ophthalmol 243(12):1263-1271

19. McIntyre BS et al (2000) Antiproliferative and apoptotic effects of tocopherols and tocotrienols on preneoplastic and neoplastic mouse mammary epithelial cells. Proc Soc Exp Biol Med 224 (4):292-301

20. Shun MC et al (2004) Pro-apoptotic mechanisms of action of a novel vitamin E analog (alpha-TEA) and a naturally occurring form of vitamin E (delta-tocotrienol) in MDA-MB-435 human breast cancer cells. Nutr Cancer 48(1):95-105

21. Tomic-Vatic A et al (2005) Vitamin E amides, a new class of vitamin $\mathrm{E}$ analogues with enhanced proapoptotic activity. Int $\mathrm{J}$ Cancer 117(2):188-193

22. Lama PJ, Fechtner RD (2003) Antifibrotics and wound healing in glaucoma surgery. Surv Ophthalmol 48(3):314-346

23. Nuyts RM, Pels E, Greve EL (1992) The effects of 5-fluorouracil and mitomycin $\mathrm{C}$ on the corneal endothelium. Curr Eye Res 11 (6):565-570

24. Crowston JG et al (1998) Antimetabolite-induced apoptosis in Tenon's capsule fibroblasts. Invest Ophthalmol Vis Sci 39(2):449454

25. Beckers HJ, Kinders KC, Webers CA (2003) Five-year results of trabeculectomy with mitomycin C. Graefes Arch Clin Exp Ophthalmol 241(2):106-110

26. Casson R, Rahman R, Salmon JF (2001) Long-term results and complications of trabeculectomy augmented with low-dose mitomycin $\mathrm{C}$ in patients at risk for filtration failure. $\mathrm{Br} \mathrm{J}$ Ophthalmol 85(6):686-688

27. Chang PN et al (2009) Evidence of gamma-tocotrienol as an apoptosis-inducing, invasion-suppressing, and chemotherapy drug-sensitizing agent in human melanoma cells. Nutr Cancer 61 (3):357-366

28. Inokuchi $\mathrm{H}$ et al (2003) Anti-angiogenic activity of tocotrienol. Biosci Biotechnol Biochem 67(7):1623-1627

29. Sylvester PW, Shah SJ (2005) Mechanisms mediating the antiproliferative and apoptotic effects of vitamin E in mammary cancer cells. Front Biosci 10:699-709

30. Weng-Yew W et al (2009) Suppression of tumor growth by palm tocotrienols via the attenuation of angiogenesis. Nutr Cancer 61 (3):367-373

31. Saito $Y$ et al (2004) Characterization of cellular uptake and distribution of vitamin E. Ann N Y Acad Sci 1031:368-375

32. Fourman S, Wiley L (1991) Tissue plasminogen activator modifies healing of glaucoma filtering surgery in rabbits. Ophthalmic Surg 22(12):718-723

33. Ophir A (1992) Encapsulated filtering bleb. A selective review: new deductions. Eye 6(Pt 4):348-352 